Ophthalmologe 2022 119 (Suppl 2):S137-S139 https://doi.org/10.1007/s00347-021-01523-0 Accepted: 11 October 2021

Published online: 20 October 2021

( $)$ Springer Medizin Verlag $\mathrm{GmbH}$, ein Teil von Springer Nature 2021

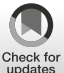

\section{Pivotal studies in glaucoma in the past 10 years}

\author{
Karl Mercieca \\ Augenklinik, Universitätsklinikum Bonn, Bonn, Germany
}

The German version of this article can be found under https://doi.org/10.1007/s00347021-01522-1.

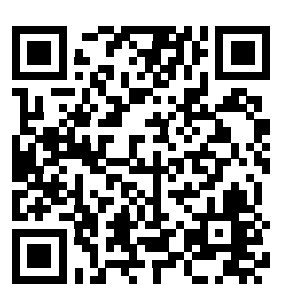

Scan QR code \& read article online
The options for diagnosis and treatment of glaucoma have expanded exponentially over the past decade, with new imaging techniques, pharmacological treatments, and novel drainage devices. As a result of this extensive choice, it can be quite difficult to decide upon which option is best for each individual patient, particularly with the extensive availability of information provided by manufacturers, researchers, and colleagues via both published and anecdotal experiences. In this Leitthema, we have decided to take a look at some of the significant landmark glaucoma studies which have been published over the past 10 years in an attempt to promote the knowledge and use of evidencebased medicine when planning investigations and treatment for our patients.

Glaucoma is a leading cause of irreversible sight loss, with an estimated worldwide prevalence of 64.3 million in 2013, increasing to 76.0 million in 2020 and 111.8 million in 2040 [1]. Because glaucoma is mainly an asymptomatic disease in the early stages, identification of risk factors and prompt diagnosis are crucial to avoid progression of the disease and significant sight loss. Once the diagnosis is made, it is also important to choose the right treatment option for the individual patient. This is usually the initiation of drop treatment and/or laser therapy, depending on various factors. In advanced or progressive disease, surgery may also need to be considered.

A lot has changed since the first large glaucoma trials started to report their findings over 20 years ago. The Ocular Hypertension Treatment Study (OHTS) determined risk factors for glaucoma and also provided the first evidence that lowering intraocular pressure (IOP) was effec- tive in delaying or preventing the onset of glaucoma in individuals with elevated IOP $[2,3]$. Although the original study was designed to look at risk factors for the development of primary open angle glaucoma (POAG) progression, many subsequent analyses provided more details on the nature and evolution of the disease, with new data still being published in recent years $[4,5]$. Similar to OHTS, the Collaborative Initial Treatment Glaucoma Study (CITGS) initially set out to examine any differences in the progression of glaucoma patients initially treated either with medical therapy or with early surgery, but subanalyses continued to be reported even as recently as 2020 [6-9]. Studies about glaucoma treatment were rather limited both for laser and surgery. The Glaucoma Laser Trial (GLT) and the Glaucoma Laser Trial Follow-Up (GLTFS) were the first studies to demonstrate the relative effectiveness of laser trabeculoplasty as an alternative to drop treatment $[10,11]$, whereas the Advanced Glaucoma Intervention Study (AGIS) looked at the long-term outcomes of different intervention sequences involving trabeculectomy and argon laser trabeculoplasty in eyes that failed initial medical treatment for glaucoma [12].

Over the past 10 years, we have witnessed a revolution in glaucoma diagnosis, imaging, and treatment. This reflects the advances that we have made in understanding the disease, and in developing diverse and effective modalities for its treatment. Although initially considered revolutionary, most of these concepts have evolved over the years and are now backed up by strong evidence, which, ultimately, should always guide our decisionmaking. Studies such as the United King- 
dom Glaucoma Treatment Study (UKGTS) and the Glaucoma Automated Test Evaluation (GATE), have evaluated previously understudied aspects of management and diagnosis, including the effectiveness of specific treatments and the value of imaging in diagnosing and monitoring glaucoma [13-16]. Several key studies, including LiGHT and ZAP, have also emerged, looking specifically at the indications and effectiveness of laser treatment for ocular hypertension and primary open angle glaucoma, and for primary angle closure suspects, respectively $[17,18]$. These studies have given us more evidence and confidence in recommending laser treatment for particular patients, although one must also bear in mind real-life evidence which is complementary to these wellplanned but more specific studies [19]. Finally, although the primary treatment for glaucoma most often involves use of eyedrops and laser, surgical intervention is still required in those patients with clinically significant progression and uncontrolled disease despite maximum medical therapy. Many surgical studies have now published long-term results which help the glaucoma specialist choose the right balance between risk and effectiveness when considering invasive procedures for their patients. Big studies such as the Tube Versus Trabeculectomy (TVT) and Primary Tube Versus Trabeculectomy (PTVT) studies have given us great insight into what to expect in terms of success rates and complications for the two main glaucoma procedures performed worldwide [20-24]. Furthermore, the Ahmed Baerveldt Comparison $(A B C)$ and the Ahmed versus Baerveldt (AVB) studies have now published 5-year data which also allow a comparison between the types of glaucoma drainage devices used.

Finally, whilst a multitude of studies have reported on various types of glaucoma devices, including the so-called minimally-invasive glaucoma surgeries, proper randomized comparisons comparing them to the "trabeculectomy" gold standard are now starting to emerge, which is important for the clinician to assess the real effectiveness of these devices [25]. Another upcoming important large study on glaucoma surgery in advanced disease, the Treatment of Advanced Glaucoma Study
(TAGS), will be an important determinant of how we treat people presenting with newly diagnosed advanced glaucoma at presentation [26]. In anticipation of these important studies, the aim of this Leitthema is to summarize what we believe are the most relevant glaucoma studies on diagnosis and treatment published within the past decade, in order to promote an evidence-based approach to glaucoma management.

\section{Corresponding address}

Dr. Karl Mercieca, MD PGCMEd FRCOphth FEBOS-GL

Augenklinik, Universitätsklinikum Bonn Ernst-Abbe-Str. 2, 53127 Bonn, Germany Karl.Mercieca@ukbonn.de

Conflict of interest. K. Mercieca declares that he has no competing interests.

The supplement containing this article is not sponsored by industry.

\section{References}

1. Tham YC, Li X, Wong TY, Quigley HA, Aung T, Cheng CY (2014) Global prevalence of glaucoma and projections of glaucoma burden through 2040: a systematic review and meta-analysis. Ophthalmology 121:2081-2090

2. Kass MA, Heuer DK, Higginbotham EJ, Johnson CA, Keltner JL, Miller JP, Parrish RK 2nd, Wilson MR, Gordon MO (2002) The Ocular Hypertension Treatment Study: a randomized trial determines that topical ocular hypotensive medication delays or prevents the onset of primary open-angle glaucoma. Arch Ophthalmol 120(6):701-713

3. Gordon MO, Beiser JA, Brandt JD, Heuer DK, Higginbotham EJ, Johnson CA, Keltner JL, Miller JP, Parrish RK 2nd, Wilson MR, Kass MA (2002) The Ocular Hypertension Treatment Study: baseline factors that predict the onset of primary open-angle glaucoma. Arch Ophthalmol 120(6):714-720

4. Budenz DL, Huecker JB, Gedde SJ, Gordon M, Kass M, Ocular Hypertension Treatment Study Group. (2017) Thirteen-year follow-up of optic disc hemorrhages in the ocular hypertension treatment study. Am J Ophthalmol 174:126-133

5. Cousins X, Chou JC, Shen LQ, Gordon MO, Kass MA, Ritch R, Pasquale LR (2020) Densitometric profiles of optic disc hemorrhages in the ocular hypertension treatment study. Am J Ophthalmol 217:10-19

6. Musch DC, Gillespie BW, Lichter PR, Niziol LM, Janz NK, Investigators CS (2009) Visual field progression in the Collaborative Initial Glaucoma Treatment Study the impact of treatment and other baseline factors. Ophthalmology 116:200-207

7. Musch DC, Lichter PR, Guire KE, Standardi CL (1999) The Collaborative Initial Glaucoma Treatment Study: study design, methods, and baseline char- acteristics of enrolled patients. Ophthalmology 106(4):653-662

8. Feiner L, Piltz-Seymour JR (2003) Collaborative Initial Glaucoma Treatment Study: a summary of results to date. Curr Opin Ophthalmol 14(2):106-111

9. Newman-Casey PA, Niziol LM, Gillespie BW, Janz NK, Lichter PR, Musch DC (2020) The association between medication adherence and visual field progression in the collaborative initial glaucoma treatment study. Ophthalmology 127(4):477-483

10. Glaucoma Laser Trial Research Group (1990) The glaucoma laser trial (GLT): 2. Results of argon laser trabeculoplasty vs. topical medicines. Ophthalmology 97(11):1403-1413

11. Glaucoma Laser Trial Research Group (1995) The glaucoma laser trial (GLT) and glaucoma laser trial follow up study: 7. Results. Am J Ophthalmol 120(6):718-731

12. AGIS Investigators (1998) Advanced Glaucoma Intervention Study (AGIS): 4. comparison of treatment outcomes within race: $7 \mathrm{yr}$ results. Ophthalmology 105:1146-1164

13. Garway-Heath DF, Lascaratos G, Bunce C, Crabb DP, Russell RA, Shah A, United Kingdom Glaucoma Treatment Study Investigators (2013) The United Kingdom Glaucoma Treatment Study: a multicenter, randomized, placebo-controlled clinical trial: design and methodology. Ophthalmology 120(1):68-76

14. Jones L, Garway-Heath DF, Azuaro-Blanco A, Crabb DP (2019) Are patient self-reported outcome measures sensitive enough to be used as end points in clinical trials?: evidence from the United Kingdom glaucoma treatment study. Ophthalmology 126:682-689

15. Founti P, Bunce C, Khawaja AP, Doré CJ, MohamedNoriega J, Garway-Heath DF, United Kingdom Glaucoma Treatment Study Group (2020) Risk factors for visual field deterioration in the united kingdom glaucoma treatment study. Ophthalmology 127(12):1642-1651

16. Azuara-Blanco A, Banister K, Boachie C, McMeekin P, Gray J, Burr J, Bourne R, GarwayHeath D, Batterbury M, Hernandez R, McPherson G, Ramsay C, Cook J (2016) Automated imaging technologies for the diagnosis of glaucoma: a comparative diagnostic study for the evaluation of the diagnostic accuracy, performance as triage tests and cost-effectiveness (GATE study). Health Technol Assess 20:8

17. Gazzard G, Konstantakopoulou E, Garway-Heath D, Garg A, Vickerstaff V, Hunter R, Ambler G, Bunce C, Wormald R, Nathwani N, Barton K, Rubin G, Buszewicz M, LiGHT Trial Study Group. (2019) Selective laser trabeculoplasty versus eye drops for first-line treatment of ocular hypertension and glaucoma (LiGHT): a multicentre randomised controlled trial. Lancet 393(10180):1505-1516

18. He M, Jiang Y, Huang S, Chang DS, Munoz B, Aung T, Foster PJ, Friedman DS (2019) Laser peripheral iridotomy for the prevention of angle closure: a single-centre, randomised controlled trial. Lancet 393(10181):1609-1618. https://doi.org/10.1016/ S0140-6736(18)32607-2

19. Khawaja AP, Campbell JH, Kirby N, Chandwani HS, Keyzor I, Parekh M, McNaught Al (2020) Realworld outcomes of selective laser Trabeculoplasty in the United Kingdom. UK glaucoma real-world data consortium. Ophthalmology 127(6):748-757

20. Gedde SJ, Schiffman JC, Feuer WJ, Parrish RK, Heuer DK, Brandt JD et al (2005) The tube versus 
trabeculectomy study: design and baseline characteristics of study patients. Am J Ophthalmol 140(2):275-287

21. Gedde SJ, Schiffman JC, Feuer WJ, Herndon LW, Brandt JD, Budenz DL et al (2009) Three-year follow-up of the tubeversus trabeculectomy study. Am J Ophtalmol 148(5):670-684

22. Gedde SJ, Schiffman JC, Feuer WJ, Herndon LW, Brandt JD, Budenz DL et al (2012) Treatment outcomes in the Tube Versus Trabeculectomy (TVT) study after five years of follow-up. Am J Opthalmol 153(5):789-803

23. Gedde SJ, Feuer WJ, Shi W, Ahmed IIK, Brandt J (2018) Treatment outcomes in the primary tube versus trabeculectomy study after 1 year of followup. Am J Ophthalmol 125(5):650-663

24. Gedde SJ, Feuer WJ, Lim KS, Barton K, Goyal S, Ahmed IIK et al (2019) Treatment outcomes in the primary tube versus trabeculectomy study after 3 years of follow-up. Ophthalmology 127(3):333-345

25. A randomized study comparing the safety and efficacy of the InnFocus MicroShuntTM glaucoma drainage system to standard trabeculectomy in subjects with primary open angle glaucoma. ClinicalTrials.gov Identifier: NCT01881425

26. King AJ, Fernie G, Azuara-Blanco A, Burr JM, Garway-Heath D, Sparrow JM, Vale L, Hudson J, MacLennan G, McDonald A, Barton K, Norrie J (2017) Treatment of Advanced Glaucoma Study: a multicentre randomised controlled trial comparing primary medical treatment with primary trabeculectomy formpeople with newly diagnosed advanced glaucoma-study protocol. $\mathrm{Br} J$ Ophthalmol 102(7):922-928 